\title{
Health Behavior Education to Prevent Coronavirus Disease-19 in Orphanages: Roleplay Strategies
}

\author{
Mahendro Prasetyo Kusumo ${ }^{1,2 * \mathbb{D}}$ \\ ${ }^{1}$ Departement of Public Health, Faculty of Medicine and Health Sciences, Universitas Muhammadiyah Yogyakarta, Bantul, \\ Indonesia; ${ }^{2}$ Master of Hospital Management, Postgraduate Program, Universitas Muhammadiyah Yogyakarta, Bantul, Indonesia
}

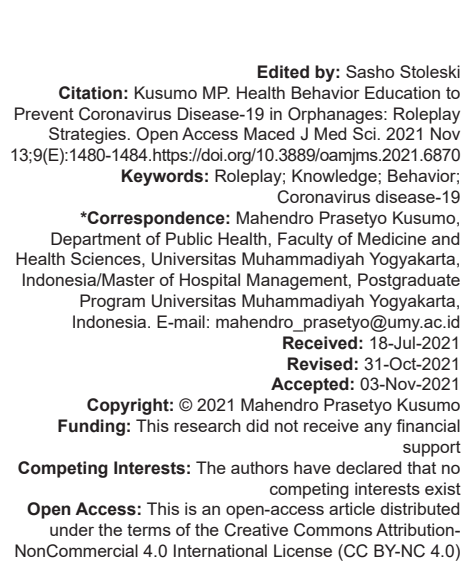

\section{Introduction}

The Coronavirus disease (COVID-19) pandemic caused by severe acute respiratory syndrome coronavirus 2 (SARS-COV-2) is a significant threat to people's lives globally [1]. The World Health Organization reported that in 2019 the number of cases of COVID-19 reached 72,851,747 million people, and 1,643,339 million people died globally. In 2020 confirmed positive cases in Indonesia reached 636,154 people and 19,248 people [2]. In Wuhan, China, 12.3\% of children tested positive for SARS-CoV-2 [3].

There is still a debate in the international community about the closure or opening of schools and the children's role in the COVID-19's transmission. The results of the previous studies explained that COVID-19 transmission cases in children were more straightforward. Era contact between children and adults (close family or playmates) is one of the causes of COVID-19 transmission [4]. The Indonesia Pediatric Society reported that since March 2020, more than 300 Indonesian children suspected of being infected with COVID-19 have died, with a death rate of $1.1 \%$ [5].
The decline in children's health conditions during the COVID-19 pandemic has hurt socio-economic conditions [4]. The process of learning and developing resources for children is the most severe impact on education. United Nations Children's (UNICEF) reported that 188 countries adopted policies to close schools during the pandemic. This condition causes a shift in the learning method from face to face to during (distant jarrah). The during method makes education difficult due to the low knowledge of human resources in digital devices. Limited internet access is also an essential concern in learning through the method, especially for the poor. The lack of access to education for children is estimated to increase from $47 \%$ to $56 \%$ due to COVID-19 [6].

Early evidence suggests that children are as likely as adults to be infected with SARS-CoV-2 but tend to be [7]. This condition has resulted in the increasing transmission of the COVID-19 virus [4]. The age group of children infected with SARS-CoV-2 was 8.9 years, and $75.6 \%$ of children exposed had a family history diagnosed with COVID-19. Most of the children exposed to COVID-19 had comorbidities, such as immunosuppression $(30.5 \%)$, respiratory problems (21.0\%), and heart problems (13.7\%) [8]. 
The World Health Organization stated that it is necessary to conduct effective education on preventing transmission of SARS-CoV-2 to slow down the transmission of the COVID-19 virus. Recommendations for wearing masks, washing hands, and maintaining distance [2]. In 2020, the Yogyakarta Provincial Government reported that positive cases of COVID-19 continued to increase.

In September 2020, it was reported that the number of positive COVID-19 cases reached 1557. One of the regencies in Yogyakarta Province that has experienced an increase in positive cases of COVID is Kulonprogo Regency. It was reported that positive cases of COVID-19 had increased by 21 new cases within $24 \mathrm{~h}$. Even in November there was an increase of up to $70 \%$ starting from October 2020 . The increase in new cases was caused by a history of contact with office clusters. This condition causes the spread of COVID-19 transmission through family members, including in the orphanage [9]. Populations living in an institution (orphanage) have a higher risk of COVID-19 infection. Limited facilities are the cause of low healthy behavior. Healthy living's low behavior is a problem to resolve immediately [10].

Health education can increase children's knowledge and behavior about the importance of healthy living habits during the COVID-19 pandemic. On the other hand, current health education is still limited to the general population, not specific to children [11]. Children are more likely to imitate adult behavior regarding adherence to health protocols during the COVID-19 pandemic. Health education in children is needed to maximize adherence to health protocols [11]. The absence of an effective vaccine or therapeutic drug is the leading cause of the spread of COVID-19. Preventive behaviors such as acceptable hygiene practices (washing hands, cough etiquette, using masks, and keeping your distance and away from crowds) are the primary keys to preventing COVID-19 [11]. Therefore, the researchers emphasize an urgent need to develop a specific COVID-19 prevention message for school children. This goal is to develop health education to increase knowledge and behavior of clean living in orphanages during the COVID-19 pandemic.

\section{Methods}

The researchers used a quasi-experimental design with a one group pre-post-test. Interventions were given in the form of health education. The study population was the orphans children living in orphanages the Yogyakarta area from November to December 2020. The study was conducted on 171 orphans children. The selection of research locations was carried out randomly. All orphans children were included in this study.

The questionnaire was given before and after the intervention. They were strongly encouraged to fill out the questionnaire, but their participation remained voluntary. The names and other personal information of study participants were protected. Each child was explained in detail by the research procedure from beginning to completion of the study and signed a consent form with orphanage caregiver.

Health education was conducted through several methods tailored to the characteristics of each child. There were two educational methods used: The roleplay method and the group discussion method. The different educational methods were based on the suitability of the development of each child in the orphanage. All children preferred roleplay education method as requested. Furthermore, a relaxed and entertaining atmosphere was the reason for choosing this method. During roleplay education, the researchers used props, posters, and videos. The instrument used was a questionnaire on knowledge of healthy living habits during the COVID-19 pandemic. The questionnaire consists of two parts, namely: Knowledge and practice of healthy living behavior. The knowledge questionnaire consists of five questions using a Likert scale, namely 3: Yes, 2: Maybe, and 1: No. The items for each of these questions are as follows. The items for each of these questions focus on the definition, causes, and prevention of COVID-19 [12].

Whereas the behavior questionnaire consists of five questions using a Likert scale, namely, 4: Always, 3: Frequently, 2: Rarely, and 1: Never. The items of each question are as follows. The items for each of these questions focus on the implementing health protocols which consist of: washing hands with soap, (2) bathing and changing clothes after returning from traveling, (3) wearing masks, (4) social distancing, and (5) bringing eating utensils and praying when leaving home.

After the roleplay education was done, the respondents were divided into small groups of four to six children to assess understanding and demonstrate appropriate behavior. Educational materials were provided related to $3 \mathrm{M}$ (in Indonesia: Menggunakan masker/wear a mask, and, Mencuci tangan/hands wash, and Menjaga jarak/social distancing) behavior, such as washing hands with six steps, wearing correct masks, and maintaining a safe distance of 1 to $2 \mathrm{~m}$. Questionnaires were distributed to participants before and after health education. Data were analyzed using SPPS.

Cronbach's alpha measured the internal consistency reliability questionnaire. Descriptive statistics were calculated, and bivariate analysis was performed. Paired-sample t-test analysis was conducted to determine the roleplay method's effectiveness in improving health protocols during the COVID-19 
pandemic. The level of statistical significance was at 0.05 .

The normality test was carried out before the difference test. The normalization test using the Kolmogorov Smirnov showed that the normally distributed data were the results of the pre-test. If there is any group it is not normally distributed the test should be using Wilcoxon test. The investigator obtained ethics approval before the beginning of the study from the Ethics Commission of the UNISA Yogyakarta.

For the qualitative study, in this section needs to explain how the study maintain the validity (trustworthiness) data obtained. The methods section written brief in two to three paragraphs.

\section{Results}

The educational method used was the roleplay method. The children group chose the "Spiderman" cartoon story as a medium to convey information. Before the stage, the children and researchers compiled scenarios and scripts. The compiled script contained messages for carrying out healthy living behaviors during the COVID-19 pandemic. Through this theater stage, education was entertaining to prevent boredom, depression, and losing interest in learning.

The investigators team acted as a player, while the children actively participated in following the stories. During the performance, there were group discussion sessions and a question and answer session. This education applied health protocols according to the WHO recommendations. The majority of respondents are male (56.7\%) aged $11-19$ years old $(79.5 \%)$. Most of them are currently still in junior high school (38.5\%) (Table 1).

Table 1: Respondent's characteristics

\begin{tabular}{lll}
\hline Characteristics & $\mathrm{n}: 171$ & $\%$ \\
\hline Sex & & \\
$\quad$ Male & 97 & 56.7 \\
$\quad$ Female & 74 & 43.3 \\
Age (years old) & & \\
6-10 y.o & 34 & 19.9 \\
$11-19$ y.o & 136 & 79.5 \\
$>20$ y.o & 1 & 0.6 \\
Education & 5 & 2.9 \\
$\quad$ Kindergarten & 45 & 26.4 \\
Elementary school & 66 & 38.5 \\
Junior high school & 54 & 31.6 \\
Senior high school & 1 & 0.6 \\
$\quad$ Bachelor degree & & \\
\hline Source: Primary Data, 2021. & &
\end{tabular}

In contrast, the results of the post-test were not normally distributed. The results showed that the mean, median, and standard deviation during the post-test were higher than the pre-test, namely, the knowledge of $9.95,9.00$, and 2.050, and the behavior of 16.50, 18.00, and 3.189.

The Kolmogorov-Smirnov normality test showed that the pre-test and post-test data on the knowledge and behavior variables were normally distributed (Table 2).

Table 2: Results of the pre-post-test

\begin{tabular}{|c|c|c|c|c|c|c|}
\hline Result & $\mathrm{n}$ & Mean & Median & Std. dev & Min-Max & $\mathrm{p}$ \\
\hline \multicolumn{7}{|l|}{ Knowledge } \\
\hline Pre-test & 171 & 9.95 & 9.00 & 2.050 & $6-16$ & $0.000^{*}$ \\
\hline Post-test & 171 & 10.26 & 10.26 & 2.087 & $7-20$ & 0.000 * \\
\hline \multicolumn{7}{|l|}{ Behavior } \\
\hline Pre-test & 171 & 15.26 & 16.00 & 3.330 & $5-20$ & $0.000^{*}$ \\
\hline Post-test & 171 & 16.50 & 18.00 & 3.189 & $5-20$ & 0.000 * \\
\hline
\end{tabular}

Figures 1 and 2 reveal an overview of the orphanage children's knowledge and behavior regarding the prevention of COVID-19 through the boxplot. The interquartile range in the post-test results is higher than the pre-test based on the boxplot.

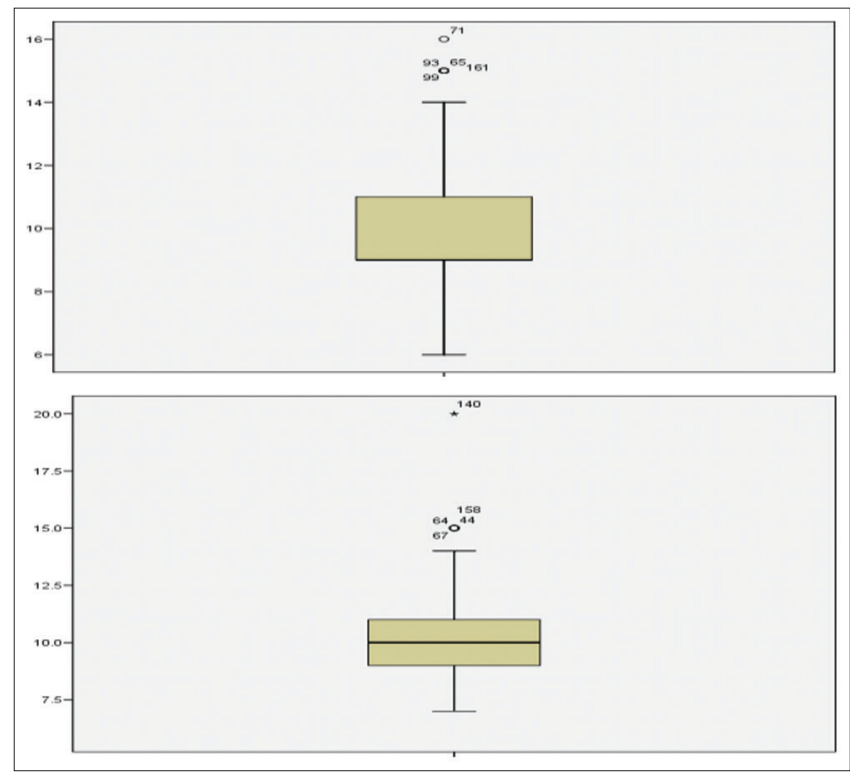

Figure 1: An overview of the knowledge of the orphanage using the boxplot. Source: Primary Data, 2021

Different tests showed differences in participants' behavior in practicing healthy living habits during the COVID-19 pandemic before and after the intervention ( $p$ $<0.05$ ), although not on knowledge (Table 3).

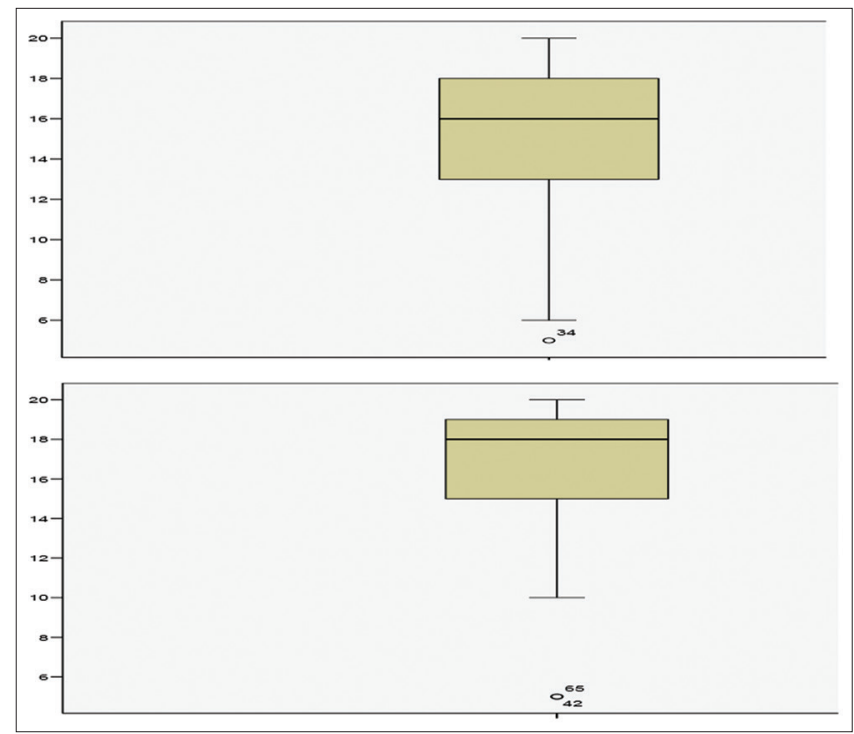

Figure 2: An overview of the behavior of the orphanage using the boxplot. Source: Primary Data, 2021 
Table 3: Differences in knowledge and behavior

\begin{tabular}{llll}
\hline Variable & Pre-test $($ Mean \pm SD) & Post-test $($ Mean \pm SD) & p-value \\
\hline Knowledge & $9.95 \pm 2.050$ & $10.26 \pm 2.087$ & 0.172 \\
Behavior & $15.26 \pm 3.330$ & $16.50 \pm 3.189$ & 0.001 \\
\hline${ }^{*}$ Significant test with paired-sample t-test $p<0.05$. Source: Primary Data, 2021.
\end{tabular}

Table should not use a column line. Table is written with Arial size 9 pt and placed within a single space below the title table. Numbering tables are using Arabic numerals. The distance between table and the paragraph is a single space. The table is put immediately after its appointment in the manuscript. The table framework is using lines size $1 \mathrm{pt}$. If the table has many columns, it can use one column format at half or full page. If the title in each table column is long and complex, the columns are numbered and its description given at the bottom of the table. The table is placed in the highest or the very bottom of each page and does not flanked by sentence. Avoid interrupted the table by page.

Images are placed symmetrically in columns within a single space of a paragraph. The image is placed in the position of the top or bottom of each page and does not flanked by sentence. If the size of the image passes through the column width then the image can be placed with a single column format. Images are placed immediately after its description in the manuscripts. Pictures are numbered and sorted by Arabic numerals. Captions placed below the image and within one single space of the image. Captions are written by using 10 pt font size, bold, capital letters at the beginning of the word, and placed as in the example.

\section{Discussion}

A relaxed and entertaining atmosphere during education had an impact on changing skills in a healthy lifestyle. According to the $\mathrm{WHO}$ recommendations, skills are seen by washing hands and using a hands on freezer and masks. They also understand more about the importance of keeping their distance and away from the crowd. During the health education process, the researchers ensured that there was no coercive element on the participants. COVID-19 pandemic impacts most of the world's population [13].

The COVID-19 outbreak has led to a level of heightened vigilance in the community which involves the extra responsibility of caring for children in need of protection and those who cannot be cared for by their biological parents as an orphanage [10]. Although the confirmed COVID-19 cases in children account for a relatively small proportion at this point, there is evidence that children are also susceptible to SARSCov-2 infection [8]. Children are a vulnerable group to become the intermediaries of transmission. In addition, children in orphanages live in congregated and relatively confined environment with limited health protection awareness. Thus, the importance to promote the welfare, protection, and care for children and staffs within the orphanage facility could never be overemphasized. National policies are needed to slow transmission and protect vulnerable populations, especially in orphanage [10], [14], [15].

Health education is an effective strategy to reduce virus transmission due to the COVID19 pandemic [16]. In addition, community-based interventions are also needed to increase self-efficacy in social support in changing behavior [17].

The low cost incurred is the choice of most countries to choose educational techniques. On the other hand, educational methods are needed according to the wishes of the participants. Mismatch in choosing educational methods leads to failure in conveying health information [16]. Education is a process of developing children's personalities that effectively transform individuals to be creative and innovative [18]. Various behavioral change theories explain that choosing health education methods can change individual behavior [19]. The previous research has confirmed that education using theater performance methods effectively changed behavior for healthy living [20]. Several educational methods have also been applied to increase knowledge and change behavior. Lecture discussion, peer group discussion, and simulation and game methods are options for changing a person's behavior [21].

Based on the previous research, education using the roleplay method was more effective for children than the group discussion method. Educational techniques through the roleplay method could improve children's understanding and experience of learning so that the messages conveyed can last longer [22]. In addition, the roleplay method through theater performances can create a pleasant atmosphere so that participants can more easily understand the material presented [20]. The roleplay method could increase children's motivation and knowledge. The roleplay method could also encourage high interaction between all participants and facilitators. The roleplay method makes it easy for educators to convey complex health information. Simultaneously, the lecture-discussion method is suitable for developing participant's critical thinking and supporting dialogue between participants and facilitators [21].

Community institutions such as nursing homes, orphanages, and prisons should pay more attention to prevention and control systems for COVID-19 [10]. The previous studies have shown that orphans know how the COVID-19 virus may harm their health. Most of them understand the proper etiquette of sneezing or coughing, although they do not understand the need to keep their distance and stay away from the crowd. The World Health Organization (WHO) and Indonesia's government require that every individual complies with health protocols during the COVID-19 pandemic. The recommended protocol is 
to wash hands, use hand sanitizer, wear a proper mask, and maintain a distance of 1.5-2 $\mathrm{m}$ when talking to people [23]. The high level of knowledge about awareness to behave healthily in orphanages has not impacted behavior the need for awareness from the orphanage caregivers to practice washing hands and use the correct hand sanitizer. Besides, adequate handwashing facilities or hand sanitizers are [24].

The accuracy in choosing the educational method is the primary key to the success of a healthy lifestyle. The orphanage group of children needs to practice healthy living habits according to WHO recommendations during the COVID-19 pandemic. A relaxed, entertaining, and not dull atmosphere is the choice of orphanage children in receiving health information. Education through acting is the choice of most children in nursing homes to prevent transmission of the virus during the COVID-19 pandemic.

\section{Conclusion}

Educational techniques through the role play method in the form of cartoon art performances are an option for children. Health education through the roleplay method creates a relaxed and pleasure atmosphere. The selection of stories scenario that will be staged as educational media is the key to success in increasing knowledge and healthy behavior in complying with health protocols during the COVID-19 pandemic. To increase motivation, the selection of story scenarios must be adjusted to the children's preferences.

\section{References}

1. Sankar J, Dhochak N, Kabra SK, Lodha R. COVID-19 in children : Clinical approach and management. Indian J Pediatr. 2020;87(6):433-42. https://doi.org/10.1007/s12098-020-03292-1 PMid:32338347

2. World Health Organization. Coronavirus Disease 2019 Vol. 2019. Geneva, Switzerland: World Health Organization; 2020. p. 2633.

3. Lu X, Zhang L, Du H, Zhang J, Li YY, Qu J. SARS-CoV-2 infection in children. N Engl J Med. 2020;382(17):1663-5. PMid:32187458

4. Balasubramanian S, Rao NM, Goenka A, Roderick M, Ramanan AV. Coronavirus disease 2019 (COVID-19) in children-what we know so far and what we do not. Indian Pediatr. 2020;57(5):435-42. https://doi.org/10.1007/s13312-020-1819-5 PMid:32273490

5. Pulungan AB. The COVID-19 pandemic and Asia-Pacific children. Asia Pac J Paediatr Child Heal. 2020;3:57-8.

6. UNICEF. COVID-19 and Children. United States: UNICEF; 2020.

7. Zimmermann $\mathrm{P}$, Curtis $\mathrm{N}$. Coronavirus infections in children including COVID-19. Pediatr Infect Disese J. 2020;39(5):355-68. PMid:32310621

8. Hoang A, Chorath K, Moreira A, Evans M, Burmeister-Morton, Burmeister $\mathrm{F}$, et al. COVID-19 in 7780 pediatric patients: A systematic review. EClinicalMedicine. 2020;24:100433.

9. Dinas Kesehatan Kabupaten Kulonprogo. Laporan Kasus Positif COVID-19. Kulonprogo: Dinas Kesehatan Kabupaten Kulonprogo; 2020.

10. Wang J, Yang W, Pan L, Ji JS, Shen J, Zhao K, et al. Prevention and control of COVID-19 in nursing homes, orphanages, and prisons. Environ Pollut 2020;266(1):115161. PMid:32645554

11. Gray DJ, Kurscheid J, Mationg ML, Williams GM, Gordon C, Kelly $\mathrm{M}$, et al. Health-education to prevent COVID-19 in schoolchildren : A call to action. Infect Dis Poverty. 2020;9:81.

12. Kusumo MP, Prabandari YS, Dewi FS. Measuring the knowledge, attitude and practice of patients with diabetes mellitus the design and development process. Int Q Community Health Educ. 2021:0272684X211022173. http://doi. org/10.1177/0272684X211022173 PMid:34148428

13. Xiang M, Zhang Z. Impact of COVID-19 pandemic on childrern and adolescents' lifestyle behavior larger than expected. Prog Cardiovasc Dis. 2020;63(4):531-2. https://doi.org/10.1016/j. pcad.2020.04.013 PMid:32360513

14. Lewnard JA, Lo NC. COVID-19 in children: The link in the transmission chain. Lancet Infect Dis. 2020;20(6):633-4. PMid:32220651

15. MunroAP, Faust SN. Children are not COVID-19 super spreaders: Time to go back to school. Arch Dis Child. 2020;105(7):618-619. https://doi.org/10.1136/archdischild-2020-319474 PMid:32371442

16. de Moura Bubadué R, Dos Santos CC, Ferreira I. Health education workshops with children in the context of COVID-19 pandemic. Rev Bras Enferm. 2020;73(2): e20200593. https:// doi.org/10.1590/0034-7167-2020-0593 PMid:33295387

17. Kusumo MP. Physical activity patterns in lecturers during Covid19 pandemic: A qualitative study. J Med Manaj Rumah Sakit. 2021;10(1):38-42. https://doi.org/10.18196/jmmr.v10i1.10829

18. Murugesan V. Modern Teaching Techniques in Education. In: Educational Technology in Teacher Education in the 21st Century, At Government College of Education for Women, Coimbatore, Conference Paper; 2019.

19. Kusumo MP. Implementasi Promosi Kesehatan di Rumah Sakit. Yogyakarta: LP3M UMY; 2020.

20. Kusumo MP, Hendrartini J, Sufro ZM, Tetra FS. Theater Performing Arts (TPA): Community Empowerment to Improve Blood Glucose Control Behavior in Yogyakarta. Int J Endocrinol Metab. 2020;18(4):e103106. https://doi.org/10.5812/ijem.103106

21. Dignan MB, Paticia A. Caee, Program Planning for Health Education and Promotion, Second Edi. Philadelpia, PA, USA: Library of Congress Cataloging; 1992.

22. Acharya H, Reddy R, Hussein A, Pettit T. The effectiveness of applied learning: An empirical evaluation using role playing in the classroom. J Res Innov Teach Learn. 2018;12(3):295-310. https://doi.org/10.1108/jrit-06-2018-0013

23. World Health Organization South-East Asia Indonesia. Update on Coronavirus Disease in Indonesia, Coronavirus Disease (COVID-19). Geneva: World Health Organization; 2020.

24. Odeka B, Akejelu R. Awareness, actions and support related to COVID-19 among orphanages in the federal territory of Abuja at onset of restricted movement in march-april 2020. Open J Public Health. 2020;2(1):1-4. 